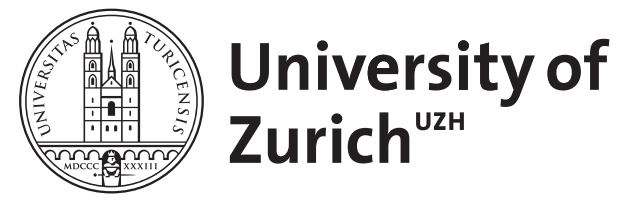

Zurich Open Repository and Archive

University of Zurich

University Library

Strickhofstrasse 39

CH-8057 Zurich

www.zora.uzh.ch

Year: 2011

\title{
Hemifacial sweating after carotid artery dissection
}

Sarikaya, H

DOI: https://doi.org/10.1016/S0140-6736(11)61102-1

Posted at the Zurich Open Repository and Archive, University of Zurich

ZORA URL: https://doi.org/10.5167/uzh-51010

Journal Article

Accepted Version

Originally published at:

Sarikaya, H (2011). Hemifacial sweating after carotid artery dissection. Lancet, 378(9791):606.

DOI: https://doi.org/10.1016/S0140-6736(11)61102-1 


\title{
Hemifacial sweating after carotid artery dissection
}

\author{
Hakan Sarikaya, MD
}

Department of Neurology, University Hospital Zurich, Switzerland

Manuscript type: Clinical Pictures

Word count: The manuscript contains 142 words

Disclosures: There is no conflict of interest. The patient consented to the publication of the case history including the photograph

Address correspondence to:

Hakan Sarikaya, MD

Department of Neurology

University Hospital Zurich

Frauenklinikstrasse 26

$\mathrm{CH}-8091$ Zürich

Switzerland

Phone $\quad 0041 / 44 / 2555686$

Fax 0041/44/2558864

E-Mail hakan.sarikaya@usz.ch 
A 40-year-old woman presented with left-sided Horner syndrome and headache. Magnetic resonance imaging revealed a wall hematoma of the left internal carotid artery (ICA), which was consistent with ICA-dissection (Panel A). When restarting with her running exercises a few weeks later she noticed unilateral facial flushing and sweating on the unaffected side during physical exertion, while the left half of her face rested pale and did not sweat (Panel B). These complaints resolved within a few minutes of rest.

Harlequine syndrome is the term for hemifacial sweating and flushing. It is very rarely reported in connection with ICA-dissection, as sudomotor and vasomotor fibers innervating the face are supposed to travel mostly with the external carotid artery. Knowledge of this cosmetically striking syndrome after ICA-dissection is helpful to prevent from further investigations and information on spontaneous amelioration by time may be sufficient instead.

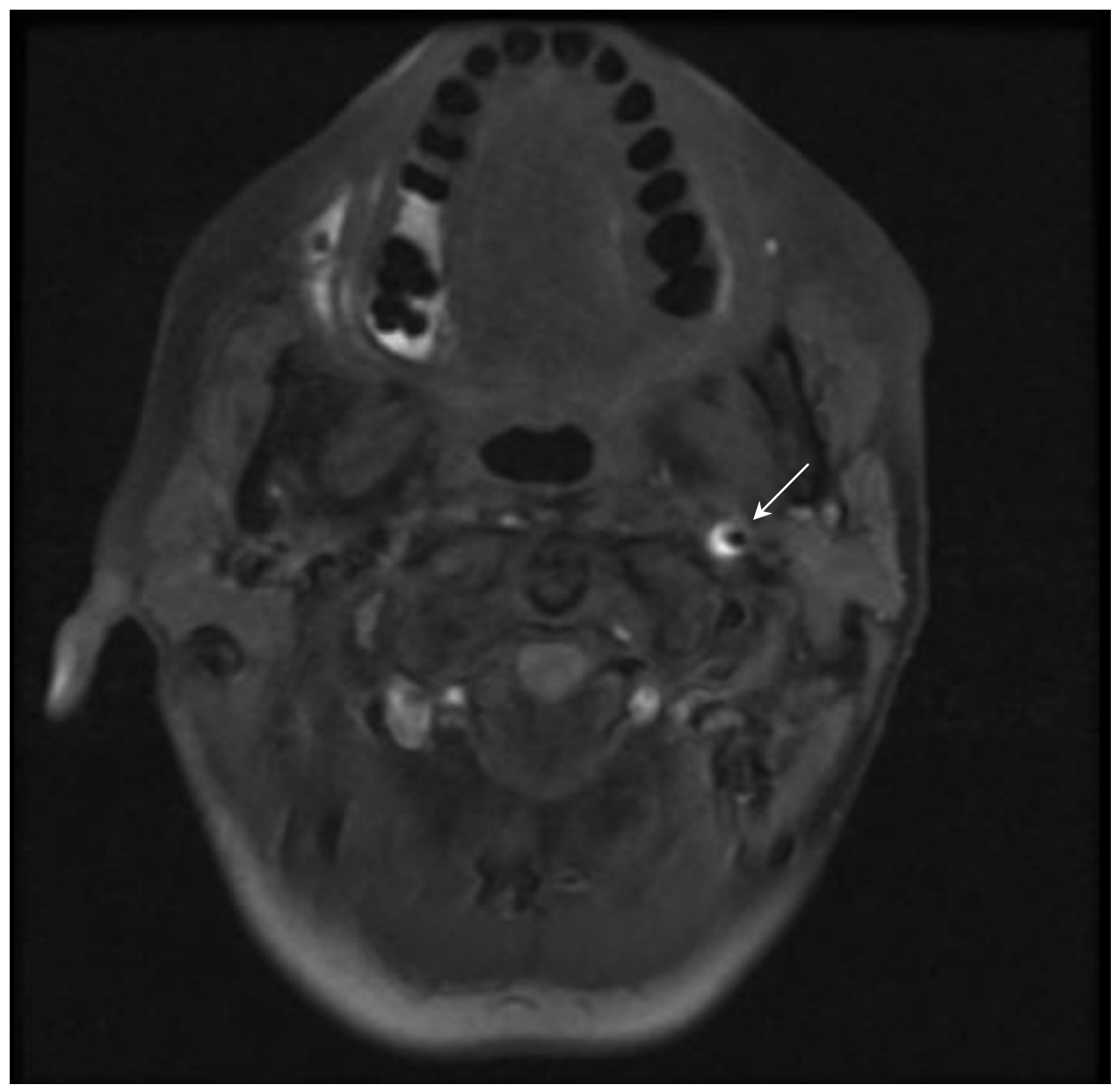

Panel A 


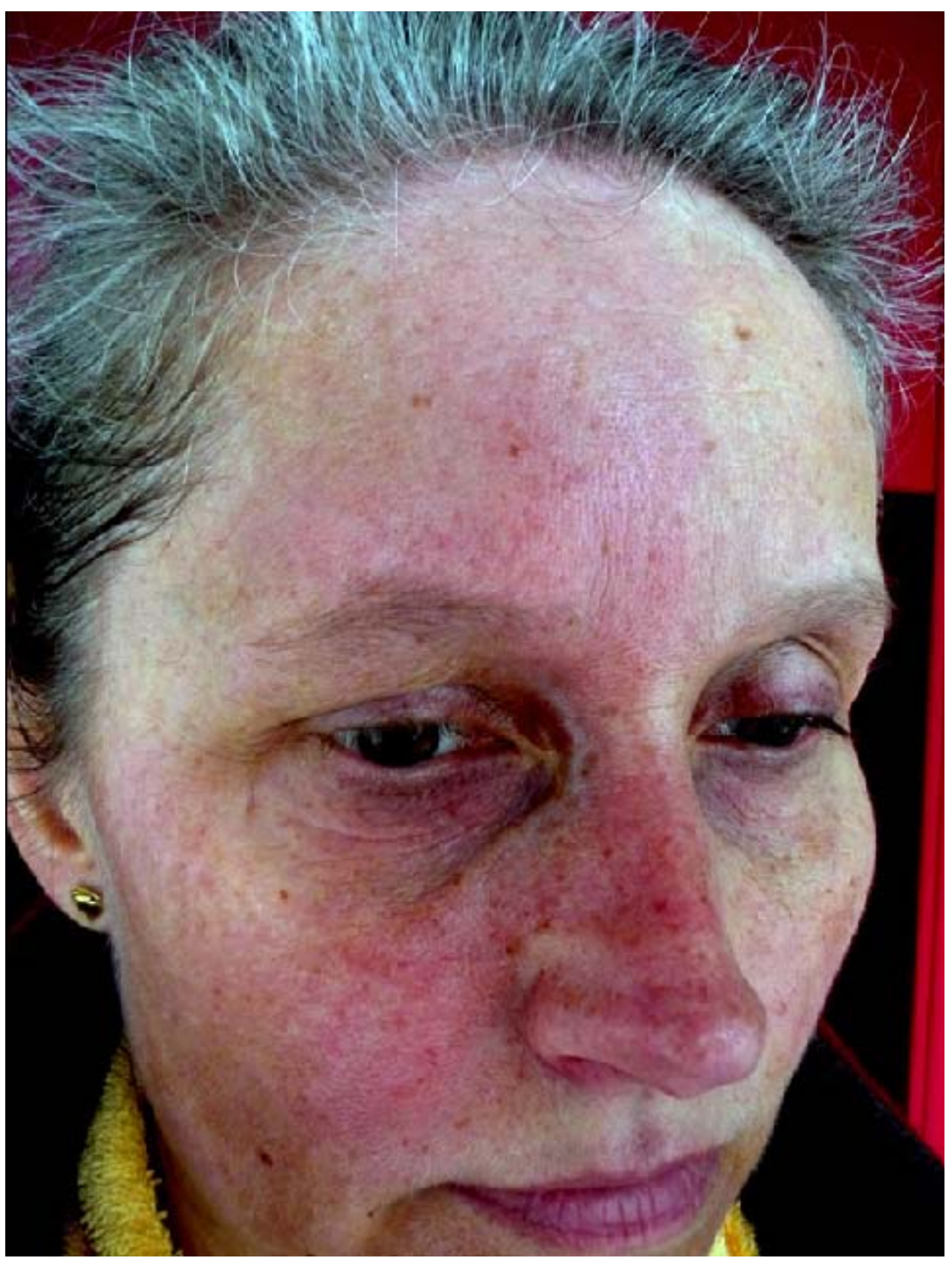

Panel B 